\title{
O PODER DA BINUBA SÔBRE OS FILHOS DO LEITO ANTERIOR
}

\author{
Euclides de Mesquita \\ Professor da Faculdade de Direito da Universi- \\ dade do Paraná.
}

Atendendo o Direito aos encargos que, pela natureza, foram reservados ao homem e a mulher na conservação da espécie, atribuiu a cada qual dos cônjuges, pelo casamento, direitos e deveres em harmonia com as suas funções naturais, embora abrindo exceções compreensíveis e que muitas vêzes o são apenas de direito, tais como as do art. 266, 277, 309 e 310 do nosso Código.

Não são pequenos nem de somenos importância os encargos que tem a mulher na sociedade conjugal, como companheira, consorte e auxiliar do marido nos têrmos do art. 240. É sua, de fato, tôda a responsabilidade interna da casa. Em regra, o que se passa portas a dentro ela é quem resolve, diretamente, ou orienta o marido para bem resolver. Por ela é que o marido está a par das necessidades da casa para providenciar no sentido de provê-las. Ao marido cabem as providências externas para a satisfação das necessidades da casa. Durante a sua ausência diária é a mulher a sua representante, a sua delegada, para sob a sua responsabilidade, resolver os assuntos que apareçam. Dela depende, mais diretamente, a bôa ou má educação doméstica que tem os filhos, assim como do marido depende a melhor ou peior situação econômica da família, a maior valorização do patrimônio material dos filhos. Embora um dos conjuges possa ter grande influência no setôr em que o outro tem 
naturalmente localizada a sua atuação, entende-se que êste ou aquêle, não podendo estar, de minuto a minuto, consultando o outro para empregar a sua atividade no campo que lhe foi reservado, ficará, sempre desta ou daquela forma, um tanto fora de tal influência e os seus atos terão assim um cunho maior da sua própria personalidade.

Por morte dum dos cônjuges, acumulam-se na pessôa do outro os direitos e deveres que competiam ao falecido. $O$ pai sobrevivente tem que entrar diretamente em contacto com as pessoas e negócios sôbre que a mulher agia, acêrca dos quais o pai tinha conhecimento ou providenciava por intermédio da mulher. Tem aumentadas as suas preocupações para saber o que se passa na sua ausência; necessitará procurar quem lhe tome conta dos filhos etc., pois lhe faltou quem teria tanto senão maị interêsse do que êle pela bôa ordem da casa, pelo bem estar do filho, pelo seu próprio confôrto e felicidade dentro do lar.

A mãe sobrevivente junta a todos os seus encargos internos os externos, que competiam ao marido, e que lhe investem no pleno exercício do pátrio poder. As suas relações para com terceiros passam a ser tôdas elas, diretas, sob a sua própria responsabilidade. Assume, de direito, a direção da sociedade conjugal, quer internamente, que já tinha, quer nas suas manifestações externas, que era reservada ao marido. Se os filhos tem bens, passa a administrá-los, com o direito atribuido a si, diretamente, de usufruí-los, como o fazia o pai, estando, assim, dispensada de prestar contas das rendas dos mesmos bens.

São equivalentes, nos casos comuns, as dificuldades que encontra o cônjuge sobrevivente no exercício das funções que o outro exercia e a que êle está deshabituado; sendo que em qualquer caso as responsabilidades jurídicas da mulher viúva são muito maiores, principalmente se há bens a administrar. Deus o sabe com que tropeços, com que aborrecimentos, luta para se desempenhar dos encargos de que se vê excepcionalmente investida. 
Recasando-se o viúvo, encontra na nova mulher, quando tenha êle filhos do leito anterior e nada tenham acertado quanto a êles em sentido contrário, alguém que, como a primeira mulher, passa a exercer o que poderíamos chamar de "mátrio poder", sôbre os seus filhos, juntamente com a direção da casa. Sendo a viúva com filhos sem bens, a recasada, salvo combinação anterior diversa, ficando ela com os filhos nos têrmos do art. 329, terão êles na nova sociedade tôda proteção que lhes vem do pátrio poder.

Quando o homem casa com mulher que tem filhos, êle tem de encarar a situação, e se aceita assim e concorda que com êles fiquem os filhos, os manterá, por certo, nos têrmos do art. 233 , n. V, pois são êles como que continuação da mulher. Semelhantemente, a mulher educará, exercerá o "mátrio poder" sôbre o filho do marido, se fôr êle o bínubo.

As obrigações normais dos cônjuges, com o novo casamento, podem crescer em volume, mais não muda o setor da atuação de cada um dêle. $\mathrm{O}$ papel do homem é mais importante, salvo rara exceções, apenas de fato, no exterior, fóra da casa. A mulher, com o novo casamento perde a sua atuação externa; aumenta a sua autoridade interna, abdicando dos negócios externos que passam a ser providos pelo marido. Quantas são empregadas ou tem qualquer função externa com que se mantém e abandonam para melhor se dedicarem a vida íntima da família?...

Embora podendo ser influenciado pela nova espôsa, o recasado é o titulado do pátrio poder e, também, como chefe da segunda sociedade, lhe cabe, essencialmente mantê-la (art. 233). O homem, quer casado em primeira núpcias, quer viúvo ou bínudo, está sempre, em face dos seus filhos, na mesma situação legal. São as mesmas as suas relações de Direito para com qualquer dêles. A mulher, não, quando é viúva, é absolutamente diversa a sua posição em relação aos filhos. Em face das suas obrigações de espôsa, o administrador, de fato, dos bens dos filhos anteriores seria o padrasto; não só os conselhos como tôdas as providências acêrca dos bens dos primeiros 
filhos, dos enteados do novo marido, seriam tomadas por êle ou por seu intermédio.

Está em Carvalho Santos (pág. 125, vol. VI do seu Cod. Civ. Int.) : "o intuito da lei também não é evitar que o filho venha a ficar sob a dependência indireta de um padrasto, tanto assim que não tira o pátrio poder ao pai que se recasa". Como vimos, o menor, de fato, só ficaria na dependência indireta do padrasto quanto à sua pessôa; relativamente aos seus bens, êle ficaria na dependência direta. Os bens do menor, apenas de direito, artificialmente, em nome, é que estariam na dependência indireta do padrasto.

0 mal que a madrasta faz ou pode fazer é, em regra, diretamente sôbre a pessôa dos filhos do seu marido; é lógico que é logo sentido por êles que se podem queixar prontamente, dando lugar a fácil e imediata verificação. 0 mal que o padrasto faria e que poderia ser feito sem a cumplicidade da mulher, da mãe dos menores mas, apenas, com a sua bôa fé, seria sôbre bens de cuja administração e disposição relativa não precisaria prestar contas a ninguém, pois contaria, sempre, com a confiança da titular, de direito, do pátrio poder dos enteados, que se não estaria a envolver em tais negócios.

É sempre direta a atuação do homem na administração dos bens. Bínubo e tendo filhos do leito anterior, possuidores de bens, administra-os, dêles tem o usufruto e pode, assim, aplicar a renda sem a ninguém prestar contas, pois, é pai, legalmente, não tem qualquer incapacidade que lhe restrinja a ação; e, perante os filhos de ambos os leitos, é a mesma a sua posição. São as mesmas as suas obrigações. Quando usar mal dos direitos do pátrio poder, está no próprio Código o remédio (art. 394).

Em regra, as obrigações da mulher na sociedade conjugal nada tem com a administração de bens. Não tem ela contacto direto com encarregados de administração. Vive informada acêrca de tais negócios, isto quando dêles não está alheia completamente, por intermédio do marido. Casada de novo, na quasi to- 
talidade dos casos, seria o novo marido quem passaria a ter os privilégios concedidos pela lei exclusivamente aos pais no exercício do pátrio poder e que, dêste ou daquele modo, a mãe se viu na contingência de exercitar duramente a viuvez.

A mãe de filho legítimo só em determinados casos tem o pátrio poder (arts 382,385 ). Entrando para a nova sociedade, volta à condição para si estabelecida no art. 240 . Vezes há que ocorre para melhor e mais depressa decidí-la ao novo pretendente o querer livrar-se dos excessivos encargos que lhe pesam, semelhantemente ao viúvo, que quer livrar-se de preocupação ou antegósando uma nova mãe para os seus filhos, uma nova dona de casa. Seria, dum modo geral, uma ficção dizer que a mulher desejaria continuar, nas segundas núpcias, com 0 pátrio poder, quando os seus encargos seriam maiores do que nas anteriores, pois aos decorrentes das segundas teria os dos remanescentes da ou das primeiras (poderiam ambos ser viúvos e ter filhos) que lhes seriam incorporados; seria uma ficção pensar que a mulher desejaria ficar, mais ainda, com os encarços extraordinários que se viu, por fôrça das circunstâncias, obrigada a exercer durante a viuvez.

Se o Código não lhe tirasse tais encargos, além de ir de encontro à sua sistemática, como veremos, deixaria de atender a uma situação de fato e, fingindo ignorar que, em tais casos, quem exerceria o pátrio poder seria o padrasto, acobertaria um privilégio que não quis estabelecer e não estabelecera. Ficaria o padrasto como administrador e usufrutuário dos bens do enteado, embora no nome da sua mulher, pois ninguém lhe inspiraria mais confiança e ela se sentiria sem jeito, fora dos seus hábitos, cogitando de assuntos que, de referência à nova sociedade, seriam cuidados pelo marido, como já foram na primeira sociedade pelo falecido. Poderia isto ser máu ou ótimo para os menores, mas seria, em qualquer caso, deixar de ver os fatos e estender, até onde não se quis, um privilégio estabelecido, com restrições, em favor, apenas, dos pais, atendendo-se à sua situação especial em face dos bens dos filhos.

As ligações de pais e filhos são tôdas sentimentais, afetivas, principalmente. $\mathbf{E}$ por isto que, quando lhe entram no meio 
estranhos, a lei passa a amparar, de modo mais prático e racional, os menores. $O$ padrasto nem precisaria ter em consideração que a sua mulher se poderia encontrar em dificuldades, ante importunos legítimos pois, sendo o enteado ainda pouco discernidor das cousas, dificimente alguém lhe traria complicações, pois a ninguém teria ela de prestar satisfação imediata.

Os pais são castigados, sofrem mais pelas restrições, que lhes são impostas de referência à espôsa e aos filhos, do que pelas que se referem aos seus bens, cousa que nem sempre existe. Os pais normais defendem como direitos, como vantagens os deveres que têm para com os seus filhos. Apezar da vida materialista e utilitária de hoje, ainda se vêem pais que brigam porque querem os seus filhos. Sacrificam-se para tê-los consigo e lutam para educá-los, amando-os sem ter em vista outras vantagens. A lei evita que um estranho, com isenção de sentimentos de pai, se aproveite do afeto que lhe tem a mãe dos menores e vinha a prejudicá-los. Previu uma situação para não ter de remediá-la. Tirou o "pátrio poder" ou melhor lhe deu margem a exercê-lo, sem, porém, a isto obrigá-la.

Dentro do nosso Código Civil não se pode dizer que a bínuba foi, injustamente, tratada, ficando em situação de inferioridade, em relação ao bínubo, quanto aos bens dos filhos do primeiro leito, nem mesmo quanto ao pátrio poder dum modo geral.

O Dr. Fausto de Freitas e Castro, quanto aos bens (Sup. Arch. Jud., vol. XLVI, pág. 81 e segs.) examina os arts. 225, 389 e 393, salientando a contradição que dêles decorre e conclui dizendo: "A bínuba perde o usufruto dos bens dos filhos do primeiro leito, se não houver dado bens a inventário; e, se houver dado bens a inventário, também perde o usufruto." Não nos parece que seja a melhor crítica a fazer, no caso. Esta seria, a nosso ver: Apesar do artigo 225, falar em viúvo ou viúva, a bínuba, a mulher, durante o tempo em que estiver casada pela segunda vez, enquanto durar a segunda sociedade conjugal, não sofrerá qualquer penalidade por ter deixado de cumprir com a exigência do n. XIII do art. 183, porque a penalidade que se atribui no art. 225 não encontra conteúdo sôbre 
que recaia, pois, decorrendo o usufruto do exercício do pátrio poder quanto aos bens dos filhos e ela o perdendo, em consequência de ter contraído nova núpcias (art. 393), não poderia ter usufruto de tais bens, que é inerente ao exercício do pátrio-poder quanto aos mesmos bens.

Assim, a mulher só será atingida pela penalidade do art. 225 se novamente enviuvar, quando, voltando ao exercício do pátrio poder, não só quanto às pessôas, como quanto aos bens dos filhos, ficará sujeita a prestar contas das rendas, pois não recuperará o usufruto.

Vê-se, portanto, que, quem está tratado desvantajosamente é o bínubo, único dos cônjuges imediatamente punido por ter deixado de cumprir a exigência legal de fazer inventário e dar partilha antes de recasar.

Quanto ao pátrio poder que o nosso Código tira à bínuba e sôbre que tanto se tem escrito, achando uns que é devido à inferioridade da mulher, concebendo outros o pátrio poder como direito próprio do pai, outros considerando a sua tirada às mãos por ódio às segundas núpcias, outros, ainda, considerando tal medida como consequência da incapacidade resultante para a mulher, do casamento, e que ela não deve poder exercê-lo, até porque, além do motivo da incapacidade, ainda existem os de se evitarem os possíveis conflitos de interêsses entre as duas famílias; finalmente, outros, como o douto Carvalho Santos - (Cód. Civ. Int. Comm. ao art. 393) que, decorrendo de sua incapacidade ela o deve poder exercer como um "munus público", devidamente autorizada pelo marido ou sendo tal autorização suprida pelo Juiz; vendo,em suma, quase todos que de tal resulta uma desigualdade de tratamento em desfavor da mulher, pois o bínubo o conserva em tôda a sua plenitude, sentimos a imposição de nos afastar dos que vêm tal, dentro do nosso Código, embora lhes reconhecendo a autoridade, para ver que o mesmo Código o que faz é, simplesmente, restabelecer, para qualquer dos cônjuges que se recasa, a mesma situação, as mesmas relações que tinham para com os filhos do leito anterior, na constância do casamento de que êles provie- 
ram. 0 poder que a bínuba perde, em face do art. 393 , é o que ela exerceu, por exceção, durante a viuvez, cumulativamente com os que exercia no casamento anterior, pois, os direitos que sôbre os filhos tinha, antes de enviuvar, ela os poderá sempre exercer, por decorrerem do art. 329. Não vemos razão porque se atribua à mulher bínuba encargos que estão fóra do setôr em que exerce a sua atividade de mãe de família, encargos êstes que ela não tinha no consórcio anterior, em vista da sua incapacidade e mesmo por fôrça da divisão natural a que, como vimos, o direito atendeu, transformando-a em legal, de direito, com as disposições reguladoras da sociedade conjugal, atribuindo a cada qual dos cônjuges encargos de real importância, embora diferenciados.

Para o Código, o homem e a mulher são encarados, no casamento, primeiramente como cônjuges, se esteja tratando de primeiras ou segundas núpcias. Antes de tudo, êles estão sujeitos ao estabelecido para cada um dêles pela casamento e que o foi, atendendo-se quanto possível aos seus encargos naturais na perpetuação da espécie. Depois, então, é que havendo necessidade de prevenir situações resultantes das incompatibilidades acaso surgidas, em face das exigências e deveres de cada cônjuge na sociedade conjugal, êle dispõe sôbre assuntos, ou melhor, prevê possibilidades como a do cônjuge já ter sido casado. Tais assuntos, semelhantes questões têm, salvo melhor juizo, de ser resolvidas com subordinação ao disposto do modo geral para o casamento.

O pátrio poder, digamos mais uma vez, foi instituido em benefício dos filhos, e principalmente, em benefício de sua pessôa, até porque nem sempre há bens. Os pais, em qualquer caso, têm para com a pessôa do filho, todos os deveres estabelecidos, sem que visem, sem que possam visar, qualquer compensação. Quando há bens, se estabelece o usofruto com um privilégio justíssimo que isenta o titular do pátrio-poder, administrador legal dos bens dos filhos, de prestar contas das rendas provindas de tais bens. Ora, a bínuba não tem a administração de tais bens e não mais se discute que o pátrio poder, chamado 
alhures pátrio dever (Arc. Jud. vol. VI, pág. 438) é instituido em benefício dos filhos. Porque ter ela o usufruto? Sob que fundamento? Como uma compensação pelo que lhe é facultado no art. 329, atendendo-se ao seu afeto materno, embora com benefícios para os filhos? Não nos parece jurídico nem atende à finalidade do usufruto legal dos bens dos filhos que seria, assim, transformado em fonte de receita para as despesas da nova sociedade, cuja mantença cabe ao marido prover, nos têrmos do art. 233, n. V. Não nos parece pois, razoável, a pergunta do Dr. Freitas de Castro (loc. cit. pág. 83) feita nos seguintes têrmos: "porque razão, sendo o usufruto inerente ao exercício do pátrio poder, quando êsse exercício está dividido, deve êle acompanhar a parte que se separa da bínuba e não ficar com a outra parte por ela conservada que é, aliás, a maior?" A propósito, não é mau que se frize, à guiza de resposta, mesmo desautorizada: 0 artigo 389, pelo lugar em que está, se refere ao pátrio poder quanto aos bens dos filhos, cujo exercício se manifesta na administração dos mesmos bens. 0 usufruto é um privilégio justo, com apoio na situação dos pais, em face dos bens dos filhos, sendo a sua finalidade precípua isentá-los duma prestação de contas injustificável. Está intimamente ligado ao galho do pátrio poder quanto aos bens dos filhos. Perdendo a bínuba o exercício do pátrio poder quanto aos bens dos filhos, não lhes tendo a administração, deixa de haver razão para ter ela o usufruto. É o próprio Dr. Freitas e Castro quem, no lugar citado, pág. 82 , lembra também, que já foi dito ser o pátrio poder instituido em benefício do filho.

0 bínubo, à semelhança da bínuda, na nova sociedade tem, sôbre os filhos do leito anterior, os mesmos direitos e deveres que tinha na constância da primeira sociedade. 0 Código não lhe deu durante a viuvez, qualquer direito extraordinário que lhe coubesse tirar quando o homem se recasasse, a fim de ser ajustado às disposições gerais sôbre o casamento, como acontece com a bínuda ante o art. 382. Os encargos de que foram acrescidos os seus deveres paternos, com a viuvez, são de ordem interna. Não lhe alteram a fisionomia legal, em face de terceiros, nas suas relações de direito fora do lar, com pessôas 
extranhas à família. São encargos de que o homem se exime, naturalmente, com o novo casamento, por ficarem, por passarem à nova consorte. $\mathrm{O}$ ódio à madrasta, a que Pereira Braga (apud Carvalho Santos, obr. cit. comm. ao art. 393, pág. 125) alude, resulta justamente disto: estar ela em contacto mais direto com os filhos no desempenho de suas funções na sociedade conjugal. 0 padrasto vive mais afastado dos seus enteados. Onde se poderia fazer sentir diretamente a sua ação seria sôbre os bens dêles, sôbre os seus rendimentos, se com a bínuba ficasem os poderes que, excepcionalmente, ela tinha na viuvez. Neste caso, seria mais difícil de se ter conhecimento dos males que recairiam sôbre os filhos, pois da má administração e aplicação das rendas dos bens dos menores, êstes seriam os mais interessados fiscais e na maioria das vêzes, descuidados de tais assuntos, não teriam discernimento bastante para perceber, prontamente, o que se estaria passando, enquanto que, exercendo-se a ação da madrasta sôbre a pessôa dêles, logo sentem os bons ou máus efeitos, a odeiam ou a estimam e mais depressa poderão conseguir, quando fôr o caso, que se os livrem do seu jugo.

A aparente desigualdade de tratamento em desfavor da bínuba se evidencia, se faz notada, desperta celeuma, nos casos em que os filhos tem bens e sôbre êles nenhum direito exerce a bínuba, enquanto o bínubo fica com o pátrio in totum. Como vimos, porém, na sistemática do Código, outra não poderia ser a solução. Êle trata o bínubo ou a bínuba do mesmo modo porque os tratára na primeira sociedade; - lhes dá a mesma soma de direitos e deveres que sôbre os seus filhos tinham na constância do casamento de que êles provieram; os encara, antes de tudo, como marido e mulher. Os outros interêsses, os demais deveres e direitos resultantes do estado pré-bínubo, são tratados com subordinação ao disposto para o casamento dum modo geral. Á bínuba não cabe a mantença da família que só coube à viúva, assim também a administração dos bens dos filhos, que estivera a cargo da viúva e de que decorra o usufruto, não era atribuida à mulher no primeiro casamento, a não ser excepcionalmente. Ao homem, em primeiras ou segunda núpcias, como na viuvez, cabe, de direito, o pátrio poder em tôda a sua exten- 
são, embora, de facto, uma bôa parte dêle e que chamáramos mátrio poder, fique a cargo da mulher, sua auxiliar nos têrmos do art. 240 do Código Civil.

As obrigações do homem, em face da nova família e dos remanescentes da antiga são as mesmas. Os seus deveres para com os filhos, para com a família, seja a primeira ou posteriores, são iguais, em face do instituto do pátrio poder (art. 380233), como iguais são os direitos e deveres da mãe, exercendo o mátrio poder sôbre os novos como sôbre os velhos rebentos seus. 0 Código fez questão de não meter pessôas estranhas nas resoluções dos pais em relação aos filhos. Deixou a cada um dêles, de logo, poderes que, de direito, podem êles exercer sem precisar da intervenção de outrem, mesmo sendo êste seu novo cônjuge. Para isto atendeu ao que determinou, dum modo geral, para o casamento. Os poderes que fariam a mulher depender do homem, êle os retirou e os que ela poderia exercitar dentro do seu raio de ação como espôsa, o Cód. fêz independer de autorização do marido. Evitando os inconvenientes e incompatibilidades decorrentes de se desviar a mulher do setor em que exerce, na sociedade conjugal, a sua ação para o setor que compete ao marido, lhe tirou os direitos do pátrio poder quanto aos bens dos filhos deixando-lhe, pelo art. 329, poderes amplos sôbre a pessôa dêles e que ela exerce independente de autorização do marido. Para que pois, quando se pretende proteger e beneficiar os filhos, sobrecarregar a mulher com encargos incompatíveis com a situação, principalmente, tendo-se em vista que os direitos que ela faria questão de exercer e que seriam mais benéficos para os filhos, são os que ela já tem e pode exercer sem dependência do marido? Podemos dizer que, quando não há bens, não precisa a mulher de autorização do marido para ter o exercício do pátrio poder necessário ao bem dos filhos do leito anterior. Não vemos vantagem, nem mesmo para os filhos, os principalmente visados, nem conveniência, em se atribuir à mulher encargos fóra da órbita em que exerce a sua ação. Não compreendemos porque se vá, como Carvalho Santos (loc. cit.) de encontro à disposição expressa do Código (art. 393), que teve em vista atender a uma situação de fato, qual fosse a de, na 
maioria das vêzes, a mulher não exercer direitos de administração dos bens nem tomar providências neste sentido sinão por intermédio do marido, procurando, como o pátrio poder autorizado criar uma situação de incompatibilidade de funções que 0 Código previu e quiz evitar.

Em face do n. ${ }^{\circ}$ IV do art. 384, entendemos que o Código só compreende atribuições dos pais em relação aos filhos, decorrentes do pátrio poder, as condições por êle regụladas, não lhes devendo, portanto, ser atribuidos direitos e deveres outros que não promanem do pátrio poder. Fóra ou além dos direitos-deveres que êles estejam, conforme o caso, em condições de exercer, não se lhes poderá dar outros, sob qualquer título que seja. 